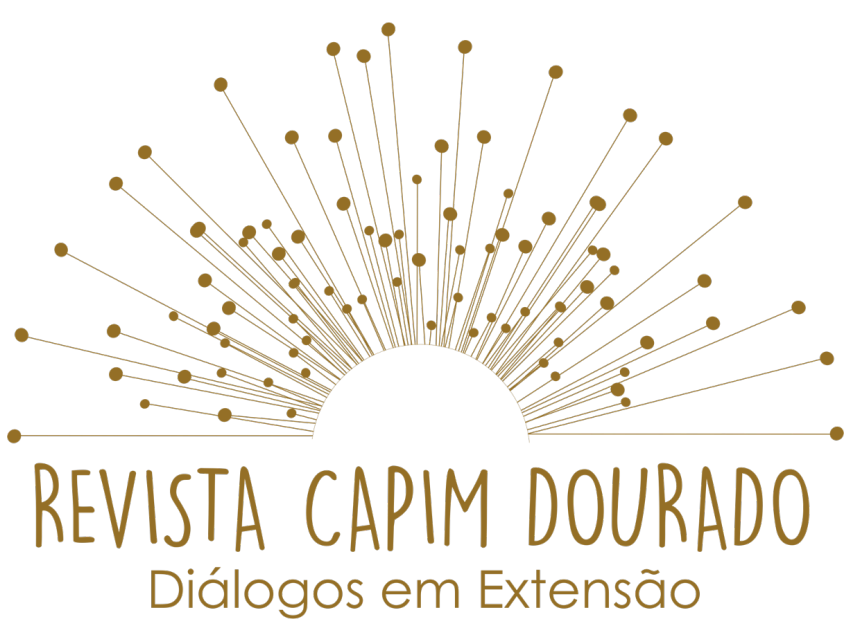

ISSN n² 2595-7341

Vol. 3, n. 1, Janeiro-Abril, 2020

DOI: http://dx.doi.org/10.20873/uft.2595-7341.2020v3n1p183

\title{
A IMPORTÂNCIA DA PESQUISA E INOVAÇÃO NO JORNALISMO DURANTE A FORMAÇÃO: relato de uma experiência
}

The importance of research and innovation in Journalism during training: an experience report

La importancia de la investigación y la innovación en Periodismo durante la formación: un relato de experiência

\section{Clifton Morais Correia ${ }^{1}$}

\section{RESUMO}

Nesse relato de experiência apresentam-se a visão de um egresso sobre a importância do curso de Especialização oferecido pelo OPAJE, da Universidade Federal do Tocantins (UFT). O egresso fala de sua trajetória de vida e profissional entrelaçadas com os processos de formação universitária em pesquisa e extensão.

PALAVRAS-CHAVES: Formação, especialização, OPAJE, Jornalismo.

\section{ABSTRACT}

In this experience report, a graduate's view of the importance of the Specialization course offered by OPAJE, from the Federal University of Tocantins

\footnotetext{
1 Jornalista. Mestrando em Comunicação e Sociedade pela Universidade Federal do Tocantins (UFT). Email: cliftonmorais@hotmail.com.
} 


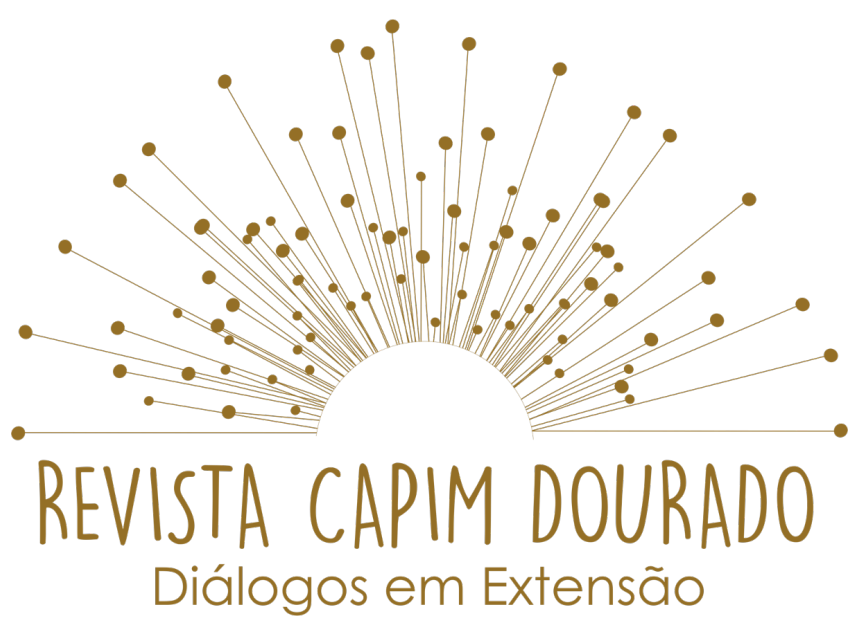

ISSN n² 2595-7341

Vol. 3, n. 1, Janeiro-Abril, 2020

DOI: http://dx.doi.org/10.20873/uft.2595-7341.2020v3n1p183

(UFT), is presented. The graduate talks about his life and professional trajectory intertwined with the university education processes in research and extension.

KEYWORDS: Training, specialization, OPAJE, Journalism

\section{RESUMEN}

En este relato de experiencia, se presenta la visión de un egresado sobre la importancia del curso de Especialización que ofrece OPAJE, de la Universidad Federal de Tocantins (UFT). El egresado habla de su vida y trayectoria profesional entrelazadas con los procesos de formación universitaria en investigación y extensión.

PALABRAS CLAVE: Formación, especialización, OPAJE, Periodismo.

Recebido em: 01.10.2019. Aceito em: 09.10.2019. Publicado em: 01.01.2020. 




ISSN n² 2595-7341

Vol. 3, n. 1, Janeiro-Abril, 2020

DOI: http://dx.doi.org/10.20873/uft.2595-7341.2020v3n1p183

Sou formado em Comunicação Social, com habilitação em jornalismo pelo Centro Universitário UnirG, em Gurupi, na região sul do Tocantins, onde me formei em 2012. A graduação era o início da melhor parte, dar o ponta pé inicial nas especializações, ampliar o conhecimento nos campos do jornalismo.

Bom, apesar de vir de uma formação mais técnica, mais de preparação para o mercado de trabalho e menos pesquisa e inovação, meu sonho sempre foi escrever, isso no caminho da linhagem científica, pesquisar bastante e encontrar coisas novas e questionáveis da área da comunicação.

Ainda no inicio da academia comecei a trabalhar na área de jornalismo. No terceiro período, recebi um convite de um amigo para ser produtor de um programa local em Gurupi, da Emissora (SBT), que é o Sistema Brasileiro de Televisão. Foi uma experiência de dois anos e por sinal muito boa, já que me deu uma outra visão do jornalismo comunitário. As aulas de teoria da comunicação e telejornalismo ficaram mais claras.

O sonho sempre foi lecionar, ser um professor do curso de jornalismo, mas para isso sabia que ainda estava começando uma longa caminhada. Mesmo atuando praticamente em todos os veículos do jornalismo, como: televisão, rádio, web jornalismo e inúmeras assessorias de imprensa, sempre quis atuar na pesquisar, ser docente.

Mas o porquê de falar, mesmo que de forma breve essa trajetória? É importante para sabermos a importância do curso de Especialização oferecido pelo OPAJE, da Universidade Federal do Tocantins. 




ISSN n² 2595-7341

Vol. 3, n. 1, Janeiro-Abril, 2020

DOI: http://dx.doi.org/10.20873/uft.2595-7341.2020v3n1p183

Assim que formei em 2012, trabalhei dois anos sem fazer curso algum, apenas com a graduação e a bagagem de jornalismo diário nas ruas. em 2014 tive a oportunidade de fazer uma Especialização em Assessoria de Comunicação e Novas Tecnologias em um Instituto em Gurupi. Foram oito meses de aprendizado, algumas coisas interessantes, mas sentia que ainda não era aquilo que eu precisava, o que realmente eu tanto queria. Pouco tempo depois, fazendo uma pesquisa no site da UFT, acessei a postagem sobre o lançamento do edital para primeira turma da Especialização em Ensino de Comunicação/Jornalismo: Temas Contemporâneos, promovido pelo Observatório de Pesquisas Aplicadas ao Jornalismo e ao Ensino (OPAJE).

Fiz minha inscrição, mandei toda documentação a Palmas e consegui a aprovação, tendo o privilégio de fazer parte da primeira turma dessa pós. A experiência, o aprendizado, foram incríveis. Precisava percorrer 480 quilômetros entre idas e voltas a cada 15 dias, onde acontecia os encontros. É que moro em Gurupi, interior do Estado e todo mês tinha o prazer de sair da minha cidade para buscar conhecimento com grandes nomes da comunicação. Eram mestres e doutores, extremamente preparados.

Entrei com uma visão micro do jornalismo, da comunicação e inovação e terminei com a alma lavada, com vontade se fazer realmente a diferença na minha área de atuação. Aulas com muita exigência, aliando a teoria e a prática.

No inicio, confesso que estava meio tímido. Afinal, passei em uma "peneira", mas ali dentro, além dos professores, tinha uma equipe de alunos muito bem preparados. Pessoas que já eram professores Universitários, mestres, especialistas, veteranos no jornalismo. Lá estava eu, no meio de verdadeiras 


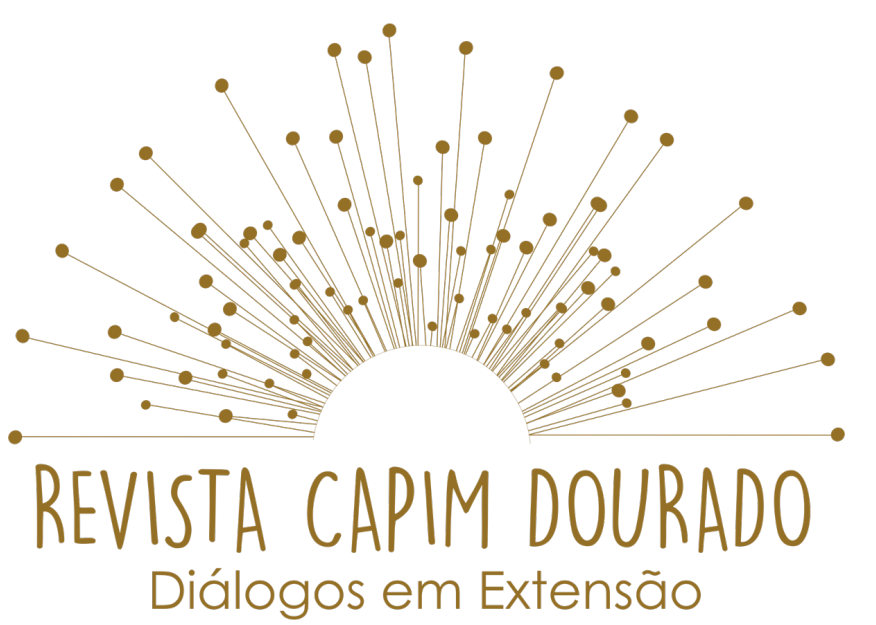

ISSN n² 2595-7341

Vol. 3, n. 1, Janeiro-Abril, 2020

DOI: http://dx.doi.org/10.20873/uft.2595-7341.2020v3n1p183

enciclopédias. Mas a timidez foi perdendo força e aos poucos fui colocando minhas pontuações durante as aulas que eram de muitos debates.

Nada de achismo, todos os posicionamentos eram baseadas em ícones do jornalismo, da comunicação e inovação. Fomos apresentados as recentes mudanças curriculares mundiais, preconizadas pelo Processo de Bolonha (ALVES; SILVA; SILVA, 2017; MELO, 2017; MOIO et al., 2017; MOTA; FERREIRA, 2017; NUNES et al., 2017; PORTO JUNIOR et al., 2017; REIS, 2017; TEIXEIRA et al., 2017). E para isso, não poderia ser diferente, exigia-se um investimento colossal da pesquisa, na leitura. Era o que me deixava ainda mais fascinado. Pesquisa, não se faz sem esforços, sem leitura exagerada e boa, sem amor e vontade. Daquelas aulas, ficava ainda mais claro que eu precisa buscar mais, me dedicar de forma excepcional para poder ter a aprovação e é claro, atingir os meus objetivos. Foi em outubro de 2015, quando comecei essa caminhada.

Produção Intelectual: I,II, III

Como disse, escrever sempre foi minha praia, quando era criança até brincava de retratar histórias com personagens fictícios. Quando adulto até publiquei um livro reportagem: "Histórias do Avô Job". Ele é Avô da minha esposa, Sarah Barbosa. Foi uma experiência boa, mas não era uma escrita cientifica. Arrisco-me até a dizer que se tivesse escrito essa obra depois dessa Especialização da OPAJE, esse livro teria ficado bem melhor.

As aulas de produção intelectual foram ministradas pelos doutores: Francisco Rebouças Porto Júnior, João Nunes da Silva, Rodrigo Barbosa e Silva 


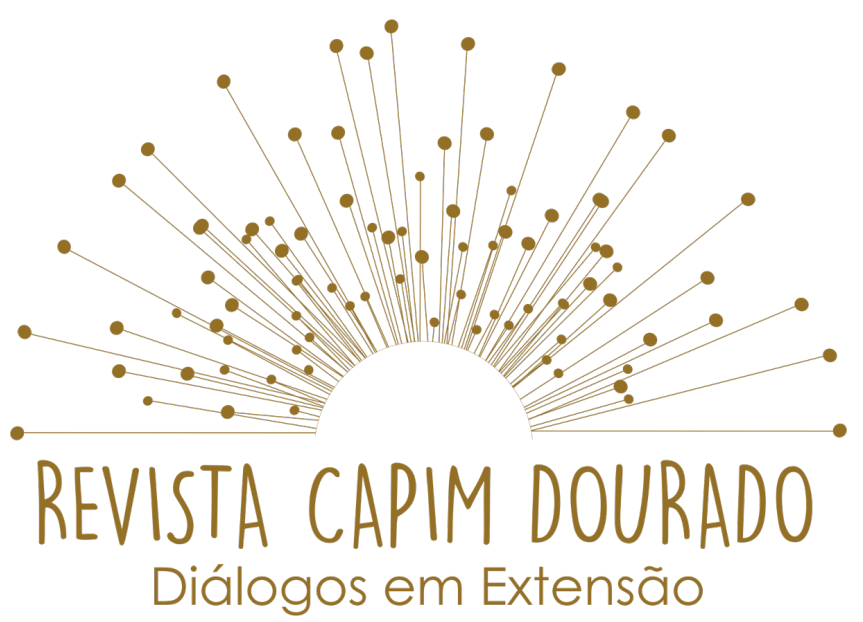

ISSN n² 2595-7341

Vol. 3, n. 1, Janeiro-Abril, 2020

DOI: http://dx.doi.org/10.20873/uft.2595-7341.2020v3n1p183

e Nelson Russo de Moraes, foi um oceano de dados importantes que durante a graduação tinha visto ainda muito pouco.

Foi fundamental essas disciplinas para o resultado dos trabalhos que seriam desenvolvidos no decorrer do curso. Em todo o percurso foram produzidos três artigos científicos. No fim, como trabalho do conclusão (TCC), houve o agrupamento desses materiais os tornando apenas um. Em cada trabalho tínhamos acompanhamento de um professor.

Como tive algumas experiências durante a caminhada do jornalismo com reportagem que tratavam sobre violência, resolvi pautar meus trabalhos nesse seguimento. Claro, a cada aula esse assunto ficava mais claro, e me dava mais inspiração para aprofundar, foi quando em uma das aulas do professor Dr. Rodrigo Barbosa e Silva, eu decidi seguir o tema para um trabalho mais a fundo. Falo mais adiante sobre isso.

A produção intelectual nos instigou a não nos conformar com o obvio, mas ir além da normalidade de uma informação. Cavar coisas novas e agregar a uma nova pesquisa que realmente contribua ao conhecimento de quem produz, dos trabalhos da academia e na vida dos profissionais durante a realização de suas atividades, além é claro, da comunidade que vai receber um produto melhor (ANDREATTA-DA-COSTA; CASTILHOS, 2017; BAPTAGLIN， L. A.; CHIERENTIN SANTI, 2018; EVANGELISTA et al., 2019; GALLERT; TACCA, 2016; LOPES et al., 2015; LUCENA; OLIVEIRA, 2019; MACHADO et al., 2018; PINHO, 2017).

Iniciação das produções 


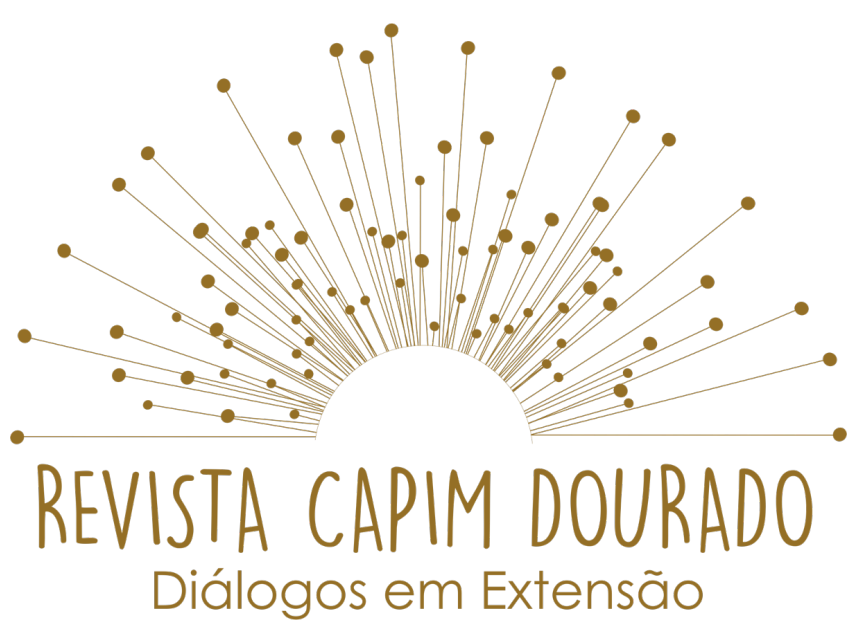

ISSN n² 2595-7341

Vol. 3, n. 1, Janeiro-Abril, 2020

DOI: http://dx.doi.org/10.20873/uft.2595-7341.2020v3n1p183

Foi na aula de Comunicação e Sociedade I: A Violência como Produto, ministrada pela DR. Rodrigo Barbosa e Silva, que a luz se acendeu para a decisão do tema que usaria para o TCC.

Sempre tinha ouvido falar em violência, convivia com isso diariamente durante a cobertura de algumas pautas jornalísticas e por causa disso, até buscava ler muito sobre temas com esse assunto. Porém, durante essa aula comecei a ter uma visão nova sobre violência. O professor era muito bem preparado, tinha uma bagagem indiscutível.

Foi a partir dai que comecei a ter uma afinidade mais com o docente e isso é algo que devemos parabenizar aos profissionais do OPAJE, além de gabaritados para tratar sobre os temas propostos, eles também tinha, mesmo com suas agendas cheias, muita vontade e disposição de servir ao aluno.

O meu tema já estava decidido, queria muito abordar a questão da violência, mas ainda estava com dúvidas de como tratar isso e fazer uma conexão com o jornalismo. Cheguei a propor algumas diretrizes ao professor, mas logo descartamos as ideias.

O lado humano dos professores do OPAJE nos deixam mais a vontade e nos dão mais liberdade, isso foi fundamental para que o DR. Rodrigo Barbosa identificasse em mim, por meio de muitas conversas uma abordagem importantíssima para colocarmos no material.

Em 2012, quando trabalhei na TV Anhanguera, emissora filiada a Globo no Tocantins, fiz a cobertura sobre casos de policiais militares que estavam envolvidos em suposto grupo de extermínio no interior do Estado. Aquilo me 




ISSN n $2595-7341$

Vol. 3, n. 1, Janeiro-Abril, 2020

DOI: http://dx.doi.org/10.20873/uft.2595-7341.2020v3n1p183

chocou muito e me deixou com muitas dúvidas com relação a abordagem dos jornalismo nos assuntos de violência e quando envolvia militares no caso.

Baseado nessas informações resolvermos produzir um artigo falando sobre os aspectos gerais da violência, para que então tivéssemos um leque maior de dados. O segundo tratamos sobre a ligação violência e jornalismo e então os casos que mencionei dos PMS. que aconteceram em Gurupi.

Nesse apanhado de informações, nasceu o artigo: "Violência e Jornalismo: Estudos sobre a violência, causas, conseqüências e coberturas jornalísticas no interior do Tocantins". Depois de muitos debates e revisões felizmente consegui a aprovação durante a apresentação.

Mas antes disso, é importante ressaltar que foi uma caminhada longa, de altos e baixos, ânimos e desânimos, mas resultou em um bom trabalho. Isso foi possível também, graças a determinação e competência dos docentes que foram fundamentais nesse processo. As aulas de produção intelectual do OPAJE fizeram a diferença.

\section{Internet, Prestação de Contas e Transparência}

Esse subtítulo é referente as aulas do professor Dr. Nelson Russo de Moraes. Por sinal, fundamentais para todo jornalista. Foi uma gama de informações sobre acessos a portais de transparência e onde realmente buscar fontes confiáveis de informação para confrontar alguns dados.

Infelizmente ainda há pecados um pouco com relação a isso no mercado de trabalho e até temos algumas dificuldades em acessar esses portais institucionais de informação. Em muitas casos na falta de tempo do fechamento 


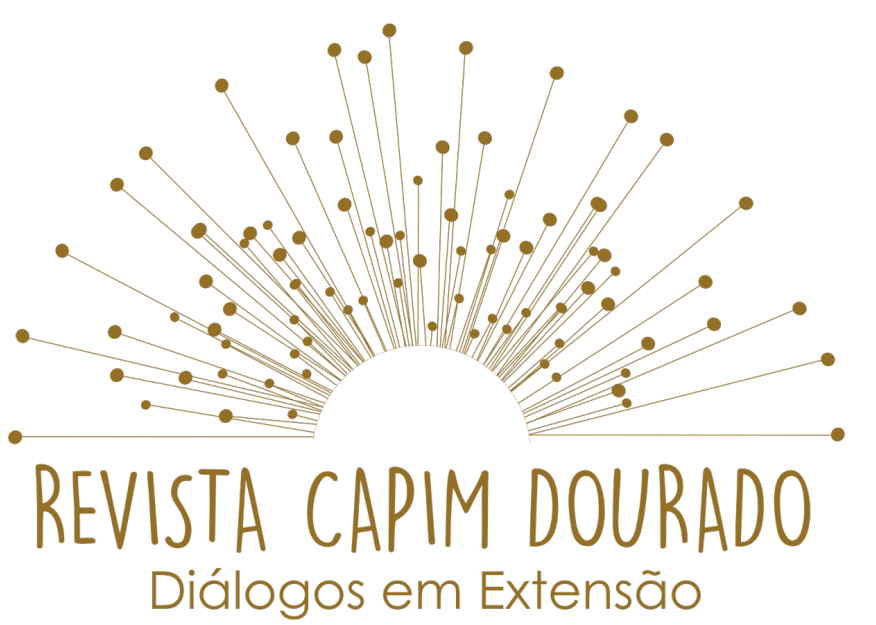

ISSN n² 2595-7341

Vol. 3, n. 1, Janeiro-Abril, 2020

DOI: http://dx.doi.org/10.20873/uft.2595-7341.2020v3n1p183

da pauta para o jornal, acabamos deixando de lado a essência da checagem. Durante as aulas foi possível ver uma outra visão sobre esse tipo de pesquisa. Agregou ao meu conhecimento profissionais e me tornou mais crítico e rígido na reprodução de algum material.

É difícil parar por aqui e não dizer sobre todas as disciplinas, todas foram fundamentais e vieram de encontro as necessidades do mercado de trabalho. Falar da "Construção da Imagem", com o DR. João Nunes da Silva, foi incrível, ver o quanto devemos ser cuidados com essa questão e saber que estamos informando com ela também, nos torna menos redundantes e com olhar mais clinico sobre texto e imagem. Afinal, os dois caminham lado a lado e precisam ser a complementação um do outro.

Estudo de gêneros, informação na inclusão digital metodologias do trabalho cientifico também foram disciplinas primordiais nesse processo de especialização.

\section{Profissionais mais preparados}

Por fim, o OPAJE nos deixou mais críticos, mais preparados para o mercado de trabalho. Saímos desses encontros com uma visão inovadora, com o oxigênio do jornalismo renovado para buscar sempre mais conhecimento, nunca nos conformando com o jornalismo quadrado (MARTINEZ, 2016; MIRANDA-PINTO et al., 2017; NEIVA; AUGUSTO, 2015; ROCHA et al., 2018; ROSA et al., 2018; SANTOS; MARTINS, 2018; SANTOS et al., 2017; SILVA et al., 2017; SILVA; SARTORI; MARTINI, 2017; SILVEIRA JUNIOR, 2015; TREVISAN et al., 2016; VILAS 


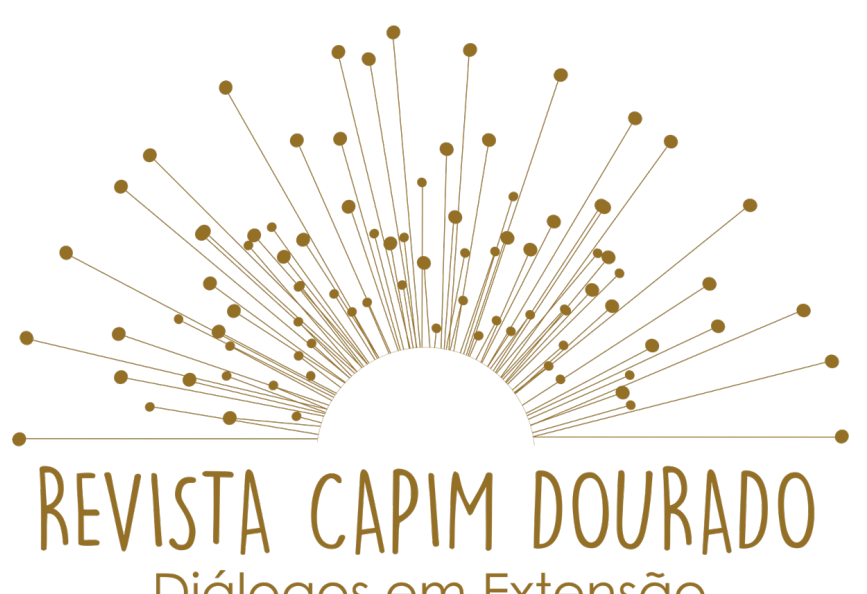

Diálogos em Extensão

ISSN n² 2595-7341

Vol. 3, n. 1, Janeiro-Abril, 2020

DOI: http://dx.doi.org/10.20873/uft.2595-7341.2020v3n1p183

BOAS et al., 2018; VIEIRA; STEFANO, 2019). É preciso sairmos da "caixinha", do tradicionalismo e ser o diferencial, inovando a cada dia.

Tudo isso só é possível com muita força de vontade, determinação e muito estudo. Quem venham as próximas, os mestrados e doutoras. Passar pelo OPAJE é ter no sangue a vontade de crescer e alcançar os sonhos, nos tornando melhores profissionais e dando uma maior contribuição para uma realidade melhor.

\section{REFERÊNCIAS}

ALVES, E. J.; SILVA, B. D. DA; SILVA, R. DA S. DA. MAPEAMENTO DOS ESTUDOS SOBRE A FORMAÇÃO DE PROFESSORES NO ÂMBITO DO PROCESSO DE BOLONHA EM PORTUGAL. Revista Observatório, v. 3, n. 6, p. 248-273, 1 out. 2017. ANDREATTA-DA-COSTA， L;; CASTILHOS， A. DA C. CONTRIBUIÇÕES DO FACEBOOK PARA A ALFABETIZAÇÃO MATEMÁTICA NO $3^{\circ}$ ANO DO ENSINO FUNDAMENTAL. Revista Observatório, v. 3, n. 5, p. 274-300, 1 ago. 2017.

BAPTAGLIN, L. A.; CHIERENTIN SANTI, V. J. AS INTERVENÇÕES ARTÍSTICAS URBANAS NO CIRCUITO DA ARTE EM RORAIMA E O POTENCIAL COMUNICATIVO DOS SABERES ARTÍSTICOS AMAZÔNICOS. Revista Observatório, v. 4, n. 4, p. 615637, 29 jun. 2018.

EVANGELISTA, F.; MARTINS, K. D.; ANGELINI, M. F. C.; ROCHA, M. J. F. SOCIEDADE DO CONHECIMENTO: O uso das TIC por docentes e as novas articulações de saberes educacionais no sudeste do Pará. Revista Observatório, v. 5, n. 5, p. 188208, 1 ago. 2019. 


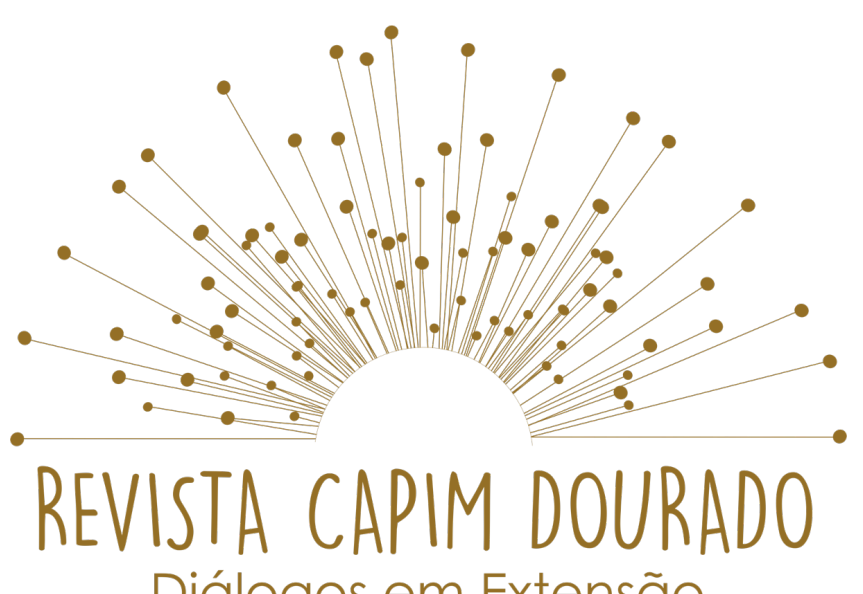

Diálogos em Extensão

ISSN n² 2595-7341

Vol. 3, n. 1, Janeiro-Abril, 2020

DOI: http://dx.doi.org/10.20873/uft.2595-7341.2020v3n1p183

GALLERT, A. Z.; TACCA, M. C. V. R. ESCOLHA PROFISSIONAL E PERSPECTIVAS DE FUTURO NA DOCÊNCIA: uma análise a partir da subjetividade dos professores. Revista Observatório, v. 2, n. 4, p. 419-441, 30 out. 2016.

LOPES, P.; PEREIRA, S.; MOURA, P.; CARVALHO, A. Avaliação de competências de literacia mediática: o caso português. Revista Observatório, v. 1, n. 2, p. 42-61, 8 dez. 2015.

LUCENA, S.; OLIVEIRA, A. A. D. DIÁRIO ONLINE NA INICIAÇÃO À DOCÊNCIA: uma experiência de pesquisa multirrreferencial. Revista Observatório, v. 5, n. 1, p. 158181, 14 jan. 2019.

MACHADO, L. S.; COSTA, T. K. DE L.; MORAES, R. M. DE. MULTIDISCIPLINARIDADE E O DESENVOLVIMENTO DE SERIOUS GAMES E SIMULADORES PARA EDUCAÇÃO EM SAÚDE. Revista Observatório, v. 4, n. 4, p. 149-172, 29 jun. 2018.

MARTINEZ, M. Reflexões sobre Jornalismo e História Oral: um campo com mais convergências do que dissonâncias. Revista Observatório, v. 2, n. 1, p. 75-91, 1 maio 2016.

MELO, A. S. E. ENQUADRAMENTO HISTÓRICO LEGAL DO PROCESSO DE BOLONHA E O SEU IMPACTO NO SISTEMA DE ENSINO SUPERIOR PORTUGUÊS. Revista Observatório, v. 3, n. 6, p. 75-141, 1 out. 2017.

MIRANDA-PINTO, M. S.; MONTEIRO, A. F.; OSÓRIO, A. J. POTENCIALIDADES E FRAGILIDADES DE ROBÔS PARA CRIANÇAS EM IDADE PRÉ ESCOLAR: 3 A 6 ANOS. Revista Observatório, v. 3, n. 4, p. 302-330, 1 jul. 2017.

MOIO, I.; ALCOFORADO, L.; VIEIRA, C. C. A DECLARAÇÃO DE BOLONHA E O REFORÇO DA ABERTURA DO ENSINO SUPERIOR A NOVOS PÚBLICOS: perceções 


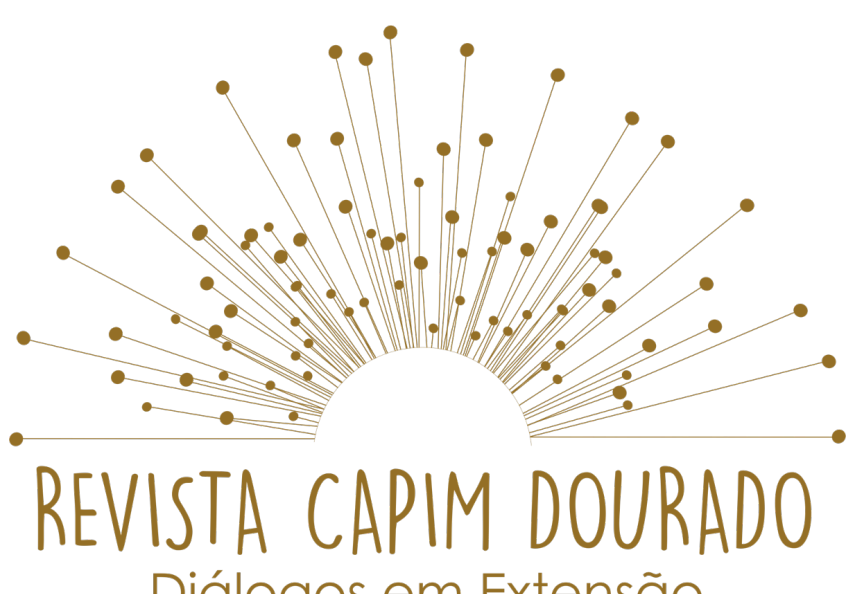

Diálogos em Extensão

ISSN n² 2595-7341

Vol. 3, n. 1, Janeiro-Abril, 2020

DOI: http://dx.doi.org/10.20873/uft.2595-7341.2020v3n1p183

de pessoas adultas que frequentam a Universidade de Coimbra. Revista Observatório, v. 3, n. 6, p. 169-201, 1 out. 2017.

MOTA, L. C. M. DE A.; FERREIRA, A. G. A FORMAÇÃO DE PROFESSORES EM PORTUGAL NO QUADRO DO ESPAÇO EUROPEU DE ENSINO SUPERIOR. Revista Observatório, v. 3, n. 6, p. 38-74, 1 out. 2017.

NEIVA, I. C.; AUGUSTO, A. Comunicólogo que brinca comunica mais?. Revista Observatório, v. 1, n. 1, p. 43-62, 30 set. 2015.

NUNES, S. G.; PORTO JUNIOR, F. G. R.; MORAES, N. R. DE. CONHECIMENTO E ORGANIZAÇÃO: indicativos pós-Bolonha de uma sociedade em construção. Revista Observatório, v. 3, n. 6, p. 338-353, 1 out. 2017.

PINHO, M. J. DE. UNIVERSIDADE E CRISE INSTITUCIONAL: perspectivas de uma formação humana. Revista Observatório, v. 3, n. 6, p. 274-315, 1 out. 2017.

PORTO JUNIOR, F. G. R.; MORAES, N. R. DE. FORMANDO PESQUISADORES PÓSBOLONHA EM PORTUGAL: relações entre a formação de graduação e o campo da pesquisa/investigação. Revista Observatório, v. 3, n. 6, p. 202-228, 1 out. 2017. REIS, E. G. DOS. O ENSINO SUPERIOR EM CABO VERDE E OS DESAFIOS DO PROCESSO DE BOLONHA. Revista Observatório, v. 3, n. 6, p. 142-168, 1 out. 2017. ROCHA, J. D. T.; NOGUEIRA, C. DA R. M. FORMAÇÃO DOCENTE: uso das tecnologias como ferramentas de interatividade no processo de ensino. Revista Observatório, v. 5, n. 6, p. 578-596, 1 out. 2019.

ROCHA, J. D. T.; NOGUEIRA, C. DA R. M.; SOUSA, J. L. DOS S.; SOUSA, G. R. DE. PRÁTICAS PEDAGÓGICAS CURRICULARES: uso das tecnologias na contemporaneidade. Revista Observatório, v. 4, n. 5, p. 673-694, 1 ago. 2018. 


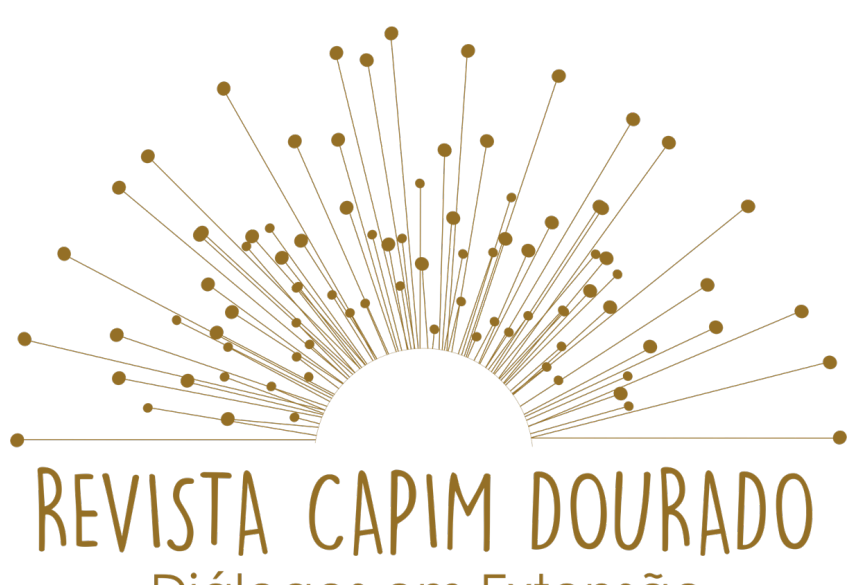

Diálogos em Extensão

ISSN n² 2595-7341

Vol. 3, n. 1, Janeiro-Abril, 2020

DOI: http://dx.doi.org/10.20873/uft.2595-7341.2020v3n1p183

ROSA, T. M. O.; SILVA, L. H. O. DA; SILVA, E. DA. EXPERIÊNCIAS DE ESTÁGIO SUPERVISIONADO NUM CURSO DE LICENCIATURA EM LETRAS: sentidos e interações nos espaços de formação. Revista Observatório, v. 4, n. 5, p. 487-511, 1 ago. 2018.

SANTOS, E.; MARTINS, V. CIBERVÍDEOS E MULTILETRAMENTOS NA EDUCAÇAO ONLINE. Revista Observatório, v. 4, n. 5, p. 231-262, 1 ago. 2018.

SANTOS, J. S. DOS; DA SILVA, E. P.; PEREIRA, I. A. C. BENEFíCIOS PEDAGÓGICOS DO USO DE EQUIPAMENTOS CELULARES EM SALA DE AULA. Revista Observatório, v. 4, n. 5, p. 536-556, 1 ago. 2018.

SANTOS, J. S. DOS; MACEDO, M. DE L. L. PEDAGOGIA DA ALTERNÂNCIA: teoria e prática na construção do conhecimento. Revista Observatório, v. 3, n. 4, p. 581602, 1 jul. 2017.

SILVA, B. D. DA; ALVES, E. J.; PEREIRA, I. C. A. DO QUADRO NEGRO AO TABLET: Desafios da docência na era digital. Revista Observatório, v. 3, n. 3, p. 532-560, 1 maio 2017.

SILVA, B. D.; SARTORI, A. S.; MARTINI, R. G. AS TECNOLOGIAS DE INFORMAÇÃO E COMUNICAÇÃO COMO AGENTES DE INTEGRAÇÃO DO CURRÍCULO COM A GLOCALIDADE. Revista Observatório, v. 3, n. 4, p. 387-406, 1 jul. 2017.

SILVEIRA JUNIOR, P. M. DA. Teoria, conhecimento e pragmática da comunicação: o paradigma pulsional. Revista Observatório, v. 1, n. 2, p. 136-155, 8 dez. 2015. TEIXEIRA, l.; DA SILVA, V. C.; MARTINS, J. L. A CONVERGÊNCIA MIDIÁTICA E AS TECNOLOGIAS MÓVEIS PÓS-BOLONHA: NOVAS PRÁTICAS SOCIAIS. Revista Observatório, v. 3, n. 6, p. 229-247, 1 out. 2017. 


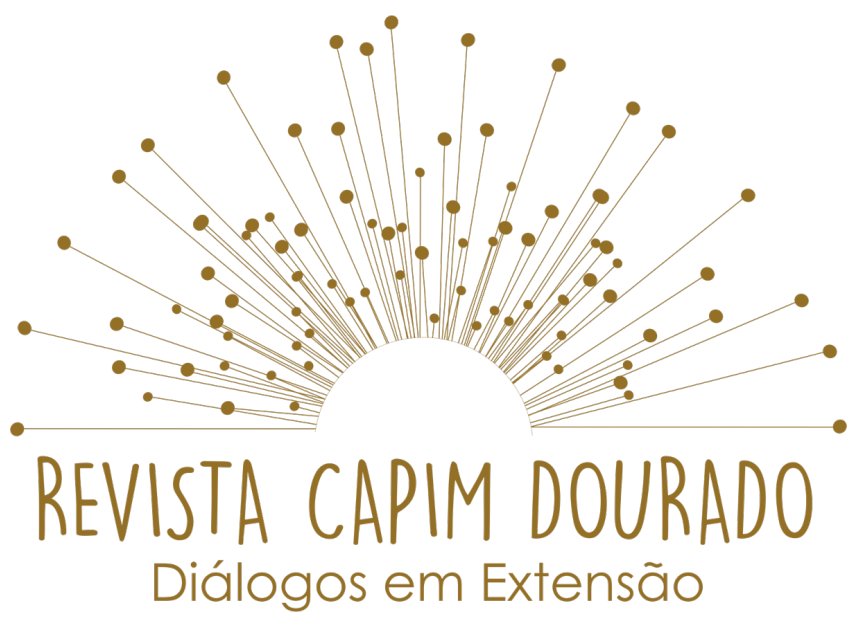

ISSN n² 2595-7341

Vol. 3, n. 1, Janeiro-Abril, 2020

DOI: http://dx.doi.org/10.20873/uft.2595-7341.2020v3n1p183

TREVISAN, M. K.; DE PRÁ, E. B.; GOETHEL, M. F. Meme: intertextualidades e apropriações na Internet. Revista Observatório, v. 2, n. 1, p. 277-298, 1 maio 2016. VILAS BOAS, F. S. DE O.; MUNIZ, D. M. S. ENTRE TRAJETÓRIAS E HISTÓRIAS: a formação do professor-leitor. Revista Observatório, v. 4, n. 5, p. 206-230, 1 ago. 2018.

VIEIRA, S. M. F.; STEFANO, L. DE M. CULTURA DOS MEMES NO AMBIENTE CONECTIVO: identidades e criação coletiva. Revista Observatório, v. 5, n. 6, p. 700-724, 1 out. 2019. 